\title{
Sociogênese do racismo: raça, ações afirmativas e democracia
}

\author{
David Junior de Souza Silva ${ }^{1}$
}

\section{Introdução}

Tenter de contraindre l'être humain à se mépriser lui-même. C'est cela que j'appelle l'enfer.

André Malraux

Este trabalho tem como tema central a discriminação racial, porém, para melhor compreensão de sua inserção no tecido social, abordá-la-ei por meio de categorias sociológicas que primem pela caracterização estrutural da desigualdade e da discriminação aos grupos oprimidos. A categoria central recrutada aqui será a de outsider (ELIAS e SCOTSON, 2000), que nos permite compreender como os grupos sociais vítimas de discriminação se encontram em uma situação, ainda que substancialmente diferente, significativamente comum na sociedade, tomando $\mathrm{o}$ cuidado, no entanto, para não reduzir a amplitude e variedade de suas experiências aos limites designados por esta categoria. Acredita-se, assim, que ao abordar o problema dessa forma, destacando-se as semelhanças da discriminação racial com as diversas formas de discriminação social, sem desconsiderar nem negligenciar as especificidades

\footnotetext{
${ }^{1}$ Universidade Federal da Grande Dourados - UFGD. Atua na área das Ciências Sociais, pesquisando a realidade de grupos subalternos, movimentos sociais, e teoria da democracia.

Contato:davi_rosendo@live.com
} 


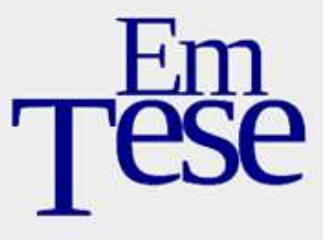

evidentes de cada caso, as manifestações concretas e a história específica de cada categoria de discriminação, poder-se-á obter, ao longo do processo, contribuições para a elaboração de um quadro mais preciso da compreensão do fenômeno da discriminação racial dentro da realidade social.

O argumento de tratá-los em suas características comuns - sem, no entanto, apagar ou desconsiderar suas especificidades - tem também potencial profícuo para a compreensão da forma como se dá a constituição do espaço social - marcado pela marginalização e estigmatização - onde são colocados os grupos oprimidos e para compreensão da ação permanentemente renovada dos grupos conservadores de conservá-los nesta posição; espera-se, com isto, obter uma compreensão do fenômeno da discriminação racial que fomente uma reflexão renovada sobre as ações políticas que objetivem combate-la, como as ações afirmativas.

A análise será desenvolvida em três esferas diferentes, cuja separação é meramente analítica de forma a abordá-las em suas histórias próprias. A primeira esfera que se analisará aqui é a que denominamos de senso comum; a segunda é a esfera da construção do conhecimento através da Ciência (e a razão para separação da Ciência e do senso comum - ambos os conhecimentos socialmente construídos e determinados será explicitada no decorrer do texto), que sabe-se ter suas raízes e fonte direta de categorias no "senso comum", e que retroage sobre este; por último, o papel do Estado na questão, sua constituição histórica e o seu potencial para manutenção deste estado de coisas e para - a partir da reformulação radical que se exige dele - a democratização das relações sociais, em prol do estabelecimento de uma ordem social efetivamente igualitária, onde a diversidade possa existir sem estar acompanhada da violência e da exclusão. 


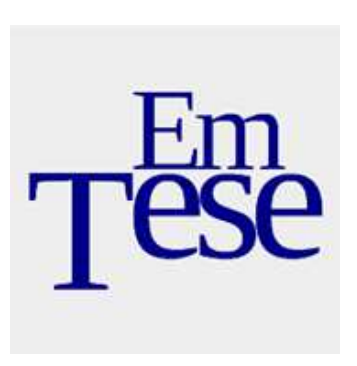

\section{Discriminação racial e marginalização}

Este trabalho centra sua reflexão em torno ao tema do racismo, entendido como uma estrutura social de poder e desigualdade, que tenta impor a inferioridade e estigmatização das pessoas por meio da sua qualificação em torno da categoria sociocultural "raça".

Conforme Avtar Brah, "Independente das vezes que o conceito é exposto como vazio, a "raça" ainda atua como um marcador aparentemente inerradicável de diferença social" (BRAH, 2006, p. 331). Ainda conforme a mesma autora, "raça" trata-se de uma noção essencialista, isto é, "uma noção de essência última que transcenderia limites históricos e culturais" (Id., Ibid., p. 331); uma noção, pois, que atribui uma essência inferior e estigmatizada aos grupos humanos aos quais se lhe impõe.

As consequências do racismo, desta estrutura de desigualdade que gira em torno da raça, são uma concepção de menor humanidade dos grupos por ele oprimidos, que justifica privação de direitos e induz ao ódio e à violência contra estes grupos. Discriminação racial é aqui entendida como os eventos e ações concretas de violação de direitos, violência e exclusão das pessoas marcadas socialmente pela categoria estigmatizadora "raça".

Racismo, assim, se refere a fenômenos de essencialização que atingem diferentes grupos sociais, caraterizados por diferentes marcadores de diferença: como a classe, o gênero, a sexualidade etc. Este artigo, entretanto, foca na questão do racismo que tem por eixo o marcador "raça", e os derivados deste, cor e etnia, como veremos logo abaixo. 
Assim sendo, no que concerne aos grupos vítimas de racismo, veremos como novas nuances do processo específico de estigmatização que sofrem podem ser trazidas à lume pela explicação estrutural da desigualdade, desenvolvida por Elias.

A hierarquização social de grupos e indivíduos, com a atribuição de conteúdos específicos a cada grupo, é evidenciada por Norbert Elias e John Scotson (op. cit.) através do par estabelecidos-outsiders. Conforme os autores, este é um "tema humano universal":

\footnotetext{
Vez por outra, podemos observar que os membros dos grupos mais poderosos que outros grupos interdependentes se pensam a si mesmos (se autorepresentam) como humanamente superiores (...) e podem fazer com que os próprios grupos inferiores se sintam, eles mesmos, carentes de virtudes julgando-se humanamente inferiores (ELIAS e SCOTSON, op. cit., p. 1920).
}

Os grupos mais poderosos fundam sua distinção e seu poder, pode-se dizer, no argumento que estiver à mão: superioridade social, moral, racial, de renda, de educação, étnica etc. Os outros grupos, subalternizados, são pelos primeiros associados à inferioridade, à anomia, à degeneração e à delinquência. Aqui vemos como o recurso à essencialização - por meio de qualquer marcador de diferença e inclusive da "raça" - é recrutado pelos grupos mais poderosos de forma a fundar sua superioridade.

Os grupos mais poderosos, os estabelecidos, se firmam como esferas de poder que tentam enquadrar outros grupos nas regras arbitrariamente estabelecidas por eles, utilizando-se de argumentos de degenerescência humana para descrever e definir (e por que não? - aprisionar) o comportamento dos últimos:

Os grupos estabelecidos veem seu poder superior como um sinal de valor humano mais elevado; os grupos outsiders, quando o poder é grande e a submissão inelutável, vivenciam afetivamente sua inferioridade de poder como uma inferioridade humana (Id., Ibid., p. 28). 


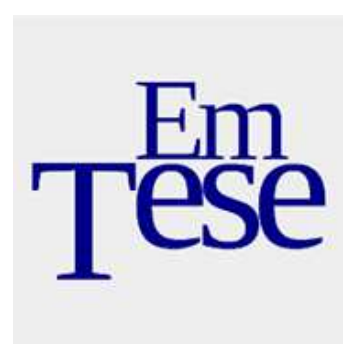

A possibilidade de se estender esta definição aos fenômenos de exclusão e discriminação de um modo geral é o que a torna um instrumental valioso para a compreensão desses fenômenos ${ }^{2}$.

Numa situação de desigualdade e marginalização específica, o marcador de diferença, que dá legitimidade a estigmatização, pode variar para preservar as estruturas de poder e desigualdade existentes. No caso estudado aqui, do fenômeno do racismo contra negros, a categoria que sustenta tal estrutura de poder, a "raça", teve seu conteúdo alterado pelos grupos mais poderosos, conforme sua validade foi questionada, de forma a conservar a relação estabelecidos-outsiders em questão.

Kabengele Munanga (2004) nos dá interessante testemunho disso, na história de como se desenvolveu o racismo e a discriminação racial contra negros no Brasil. Munanga fala da permanência do racismo, mesmo após a comprovação científica de que raças biológicas não existem, e até da ampliação do escopo do racismo, que se alimenta agora da noção de etnia.

Já no fim do século passado e início deste século, o racismo não precisa mais
do conceito de raça no sentido biológico para decretar a existência das
diferenças insuperáveis entre grupos estereótipos. Além da essencialização
somático-biológica, o estudo sobre o racismo hoje deve integrar outros tipos
de essencialização, em especial a essencialização histórico-cultural. Embora a
raça não exista biologicamente, isto é insuficiente para fazer desaparecer as
categorias mentais que a sustentam. (...) Enquanto o racismo clássico se
alimenta na noção de raça, o racismo novo se alimenta na noção de etnia
definida como um grupo cultural (MUNANGA, op. cit., p. 10).

Em outro momento da reflexão, Munanga complementa: "O conteúdo da raça é morfobiológico e o da etnia é sociocultural, histórico e psicológico" (Id., Ibid., p. 12). O

\footnotetext{
${ }^{2}$ Esta opção não pretende de modo algum limitar a condição/experiência social de tais grupos subalternos ou marginalizados ao significado que encerra e restringe a categoria outsider, e nem pretende deslocar o foco explicativo da situação social desses grupos para algo presente em sua natureza, intrínseco a eles, em detrimento de enxergar a 'causa' da condição social em que estão onde esta verdadeiramente se encontra: nas relações sociais que lhes foram impostas.
} 


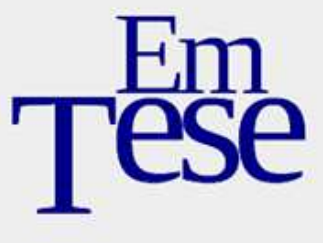

racismo que era praticado então com base na noção de 'raça', passou a ser baseado na noção de 'etnia'; a discriminação, em sentido amplo, se opera então contra grupos que tenham concepções simbólicas diferentes do grupo estabelecido, qualquer que sejam estas concepções. Nas palavras de Munanga, "Estamos entrando no novo milênio com a nova forma de racismo: o racismo construído com base nas diferenças culturais e identitárias.” (Id., Ibid., p. 11).

Quando estas classificações, e seu conteúdo hierárquico e violento, estão disseminadas já no tecido social, consegue-se compreender sua permanência e reprodução. Pode-se compreender facilmente, por exemplo, como a classificação e hierarquização racial ganharam força quando Lineu, citado por Munanga, lhes aferiu caráter científico - e isso, evidentemente, num contexto de valorização da Ciência. Porém, Lineu não estava 'inventando', por assim dizer, estas classificações; elas já eram difundidas e presentes na sociedade na qual este cientista se inseria.

Porém, em termos das preocupações que traz este texto em torno a uma sociogênese do racismo, é tarefa primordial também identificar, numa relação estabelecidos-outsiders, como estas classificações e marcadores sociais de diferença se formam no seio social, se estabelecem e adquirem esse conteúdo hierarquizante; ou se é, antes, um conteúdo hierarquizante que surge primeiro no tecido social, e depois busca fundamentar-se em distinções e classificações que puder obter ou criar.

Quanto à gênese destes marcadores e o diferencial de poder que emerge imbricado a eles, Simone de Beauvoir (1970) nos oferece reflexões importantes. Filósofa que envidou grandes esforços para compreender o problema da discriminação social - ainda que sua preocupação concreta seja outra, a da condição das mulheres -, nos abre uma perspectiva interessante sobre este problema da origem do marcador social estigmatizador e marginalizador do outsider ao afirmar que "a categoria do Outro é tão 


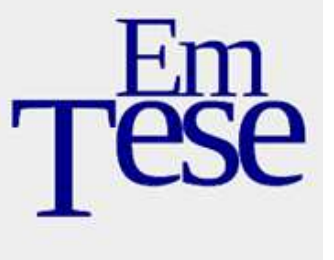

original quanto a própria consciência" (BEAUVOIR, op. cit., p. 11), e, em seguida, ao afirmar, numa clara adesão à tradição hegeliana, que "a alteridade é uma categoria fundamental do pensamento humano. Nenhuma coletividade se define como Uma sem colocar imediatamente a Outra diante de si." (Id., Ibid., p. 12).

Conforme a autora, a consciência humana opera marcando diferenças. O modo de ser específico da consciência é relacional, necessita marcar diferenças e oposições.

Em seguida, Beauvoir cita o próprio Hegel, segundo o qual, nas palavras da autora, "descobre-se na própria consciência uma hostilidade fundamental em relação a qualquer outra consciência; o sujeito só se põe em se opondo; ele pretende afirmar-se como essencial e fazer do outro o inessencial, o objeto" (Id., Ibid., p. 13).

Numa relação estabelecidos-outsiders, que caracteriza a estrutura de poder e desigualdade do racismo, fica evidente como este modo de ser da consciência, de fazer do outro o inessencial, é tendencialmente levado para fazer desta oposição uma hostilidade violenta, que não quer apenas a diferenciação do outro, porém também sua submissão e aniquilamento.

A origem e o impulso desta atividade humana de classificação hierarquizadora - a atividade que cria os marcadores de diferença a que fazem recurso os grupos mais poderosos numa relação estabelecidos-outsiders - permanece por ora esfera apenas de especulação filosófica. Entretanto, pode-se reunir explicações científicas que, conquanto sem atingir o âmago do problema da origem da atividade humana de classificação hierarquizadora, ou da constituição da alteridade hierarquizada, fornecem quadro elucidativo da presença destas classificações e marcadores no tecido social, como componentes do dito 'senso comum'. 


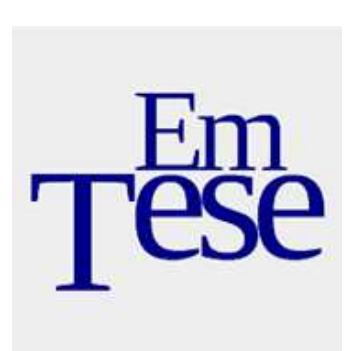

A justificativa, mencionada anteriormente, para se considerar como distintos o conhecimento do 'senso comum' do conhecimento científico é a proposta de Antônio Sérgio Alfredo Guimarães (2003) como forma de construir um instrumental para estudo do racismo. Na terminologia de Guimarães, a distinção entre os dois tipos de conhecimento é expressa na existência dos 'conceitos nativos' e dos 'conceitos analíticos'.

Para Guimarães, os conceitos nativos consistem em um conhecimento cujo conteúdo não é produto nem passa necessariamente por nenhuma avaliação crítica para ser aceito como válido e ter relevância prática para dirigir a vida e as ações das pessoas em seu cotidiano. Faz parte de sua essência mais íntima não carecer de validação por outros (e, pode-se acrescentar, de certo modo, ser capaz de continuar existindo - e tendo influência, não só significativa, mas mesmo decisiva na vida das pessoas - mesmo após a desconstrução de seu conteúdo pelo conhecimento científico). Fazem sentido para a sociedade, produtos dela que são, e são por ela reconhecidos independentemente de validação ou comprovação de qualquer gênero.

Os conceitos analíticos, diferentemente, apenas têm validade mediante legitimação científica. Esta distinção proposta por Guimarães possibilita pôr em evidência a questão da percepção da sociedade sobre si mesma e do papel dos marcadores sociais de diferença na estruturação da visão de mundo das pessoas. Ao propor a categoria de "conceitos nativos" o autor nos mostra exatamente que os marcadores de diferença, instrumentais do racismo, como construções sociais nascem do próprio seio social, e que o conhecimento científico - que reivindica uma legitimidade e uma autoridade maior - é edificado sobre estas construções e marcadores. Guimarães aponta assim para a falsidade da reivindicação científica de ser portadora de um saber "legítimo", "verdadeiro", absoluto, a-histórico, a-social, neutro e 


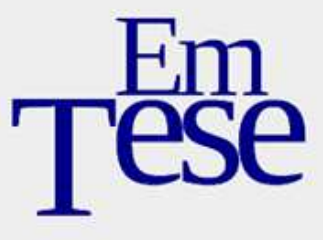

isento das paixões humanas, e para seu vínculo e compromisso com as estruturas de desigualdade e poder e inclusive com as relações estabelecidos-outsiders.

Assim, de componente da visão de mundo dos indivíduos, compreende-se como esses marcadores de diferença, que carregam o racismo e nos quais este se apoia, na forma de conhecimentos, figuras, valores e preconceitos, passam a fazer parte, com novo status, do conhecimento científico, onde têm maior poder. A Ciência não absorve do tecido social no qual se desenvolve apenas a sintaxe e o universo semântico de sua linguagem, porém seu conteúdo vincula-se às relações estabelecidos-outsiders desta sociedade.

Este enraizamento social do "saber" científico, as construções sociais sobre as quais este se edifica, são aprofundadas por Nancy Stepan (1994), num texto em que mostra detalhadamente, a partir da analogia raça-gênero, os passos da constituição da reflexão sociológica acerca da desigualdade humana. $\mathrm{Na}$ próxima seção, compreenderemos como a ciência se vincula à relação estabelecidos-outsiders e como empresta maior poder e validade a esta mesma relação, formando parte assim do complexo fenômeno do racismo.

\section{Dos grilhões da ciência: o pensamento humano à rédea curta}

Nancy Stepan mostra como a Ciência é constituída de metáforas e analogias, e como estas são fortemente ligadas com os valores fundamentais de uma cultura.

A Ciência que conhecemos, cujas bases foram formalizadas no início do século XIX, é a Ciência Positivista. Os positivistas, dentre outras coisas, acentuaram a diferenciação entre linguagem metafórica e linguagem científica, associando a primeira 


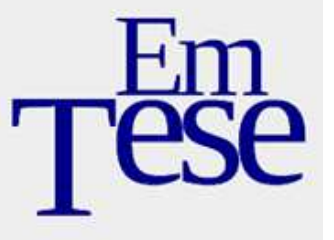

à imaginação, à fantasia e mesmo à falsidade, e creditando à segunda a qualidade de conhecimento não-metafórico, empírico, apolítico e universal. O positivismo rechaçava a metáfora como um obstáculo mesmo ao conhecimento científico. Hoje, com o avanço das pesquisas sobre a própria constituição social da Ciência, observa-se que as metáforas e analogias são na verdade "partes insubstituíveis da maquinaria linguística de uma teoria científica (...) não são apenas auxiliares psicológicos para a descoberta científica ou esquemas heurísticos, mas elementos constitutivos da teoria científica" (STEPAN, op. cit., p. 73).

Stepan demonstra em seu texto qual o papel das metáforas e analogias na estruturação da percepção humana, e, portanto, na constituição do conhecimento científico. Começa afirmando que, "na ciência, metáforas e analogias não são arbitrárias, nem meramente pessoais", e nem nunca serão, buscando, assim, atentar para a origem social das metáforas, ao evidenciar uma coincidência delatora: "os valores básicos de uma cultura são normalmente compatíveis com 'a estrutura metafórica dos conceitos mais fundamentais na cultura'." (Id., Ibid., p. 77). Para em seguida, baseada nestes termos, mostrar que uma das razões para aceitação de um determinado paradigma, teoria ou explicação científica é exatamente a sua congruência com as premissas e/ou expectativas culturais.

A importância dessa observação é melhor dimensionada quando Stepan afirma que sem as metáforas e analogias a Ciência simplesmente não existiria; elas são, pois, de fato, elementos constitutivos da própria Ciência. A metáfora e a analogia, conforme Stepan, não se reduz apenas a comparações entre enunciados, mas consiste na produção de novos significados, mediante a interação dos enunciados anteriores: "o [novo] significado é um produto da interação entre as partes da metáfora” (Id., Ibid., p. 80). 
As interações metafóricas envolvem um complexo sistema de implicações, valendo-se frequentemente de uma linguagem especializada, possivelmente para disfarçar a arbitrariedade das analogias. "De fato, é justamente a falha em perceber 'arbitrariedades' que faz com que as metáforas ou analogias particulares sejam aceitáveis como ciência." (Id., Ibid., p. 76). Quanto ao funcionamento e à utilidade prática dos sistemas metafóricos, Stepan assim o descreve:

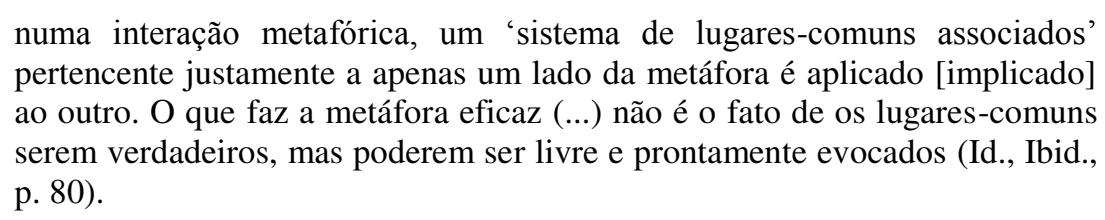

Além daquela congruência e presteza na corroboração dos valores básicos de uma cultura. Esta corroboração explica o lugar das representações científicas, que conferem legitimidade aos marcadores sociais de diferença, nas relações estabelecidos-outsiders.

As metáforas e analogias induzem os cientistas a enxergar similaridades que antes não eram notadas. E aqui entra um dos pontos-chave para se compreender a natureza do funcionamento da metáfora na constituição de novos conhecimentos. As similaridades, conforme Nancy Stepan, não são 'encontradas', 'percebidas', mas precisam ser estabelecidas. E as metáforas e analogias agem precisamente na construção e estabelecimento de similaridades. "É a metáfora que nos permite perceber similaridades que ela mesma ajuda a construir. (...) As metáforas, então, a partir de sua capacidade de construir similaridades, criam novos conhecimentos.” (Id., Ibid., p. 85). Ao mesmo tempo, existe uma certa força distorciva e tendenciosa na metáfora. Ela opera algo que se poderia chamar de 'redescrição', isto é, força o leitor a 'entender' um dado aspecto da realidade em outros termos.

A metáfora induz, organiza, então, a percepção do cientista em relação ao que, precisamente, será observado na natureza, e, especialmente, a como será observado. 
Do que se depreende do texto de Stepan, a Ciência é constituída de metáforas; estas são fundadas, ou melhor, são produto das categorias e valores mais fundamentais de uma cultura; esses valores, sabemos, são completamente arbitrários, e sujeitos à manipulação pelos grupos dominantes em cada sociedade. Mediante, pois, o evidenciamento de como a Ciência é fundada sobre esses valores, e de como eles entram na sua constituição, pode-se enxergar um razoável panorama, portanto, do quanto o conteúdo da Ciência é composto de elementos arbitrários e de tendências hierarquizadoras e comprometidas com a legitimação das desigualdades sociais e da dominação de determinados grupos sobre outros.

Vincular a reflexão de Stepan à análise da complexidade do fenômeno do racismo e das relações estabelecidos-outsiders não se trata de imiscuir no pensamento da autora reflexões alheias a ela. A própria autora aponta o "papel dos fatores sociais, políticos ou econômicos" na constituição de metáforas e analogias de um modo geral, e, portanto, "na produção de novos significados" (Id., Ibid., p. 91) na Ciência.

Permanecessem circunscritos à esfera científica, os efeitos nocivos dos sistemas de implicações metafóricas não seriam tão grandes. Entretanto, eles têm consequências sociais e morais para a intelectualidade e para a cosmovisão da sociedade como um todo. Em forma de Ciência, eles expandem o assentimento às pressuposições culturais subjacentes às analogias que os deram origem. E tem consequências sociais gravíssimas ao colaborarem na perpetuação do status quo social. A Ciência, assim, retroage sobre os valores da sociedade na qual se insere, confirmando-os e reafirmando-os. Existe uma "tendência das metáforas se tornarem dogmáticas e serem vistas literalmente como verdadeiras e não metafóricas [e] é particularmente forte na Ciência em razão da identificação da linguagem científica com a linguagem da realidade e objetividade" (Id., Ibid., p. 90). 
O papel da metáfora na construção e direcionamento da Ciência, e a retroação desta sobre a sociedade, na corroboração e na ampliação do assentimento às premissas culturais, são bem resumidos nas próprias palavras de Stepan:

Reiterando o fato de uma analogia ou metáfora não apresentar diretamente uma natureza preexistente, mas, em vez disso, ajudar na construção 'daquela' natureza, a metáfora gera informações que se adaptam a ela e guarda [esconde] informações que aparentemente a contradizem, de tal modo que a natureza é observada via metáfora, e esta se torna parte da própria lógica da Ciência (Id., Ibid., p. 89-90).

A contribuição dos cientistas foi elevar analogias guardadas até então no inconsciente para uma teoria embaraçosa, ampliar os significados ligados às analogias, expandir seus alcances via novas observações e comparações, e dar a elas previsão por meio de vocabulário especializado e novas tecnologias. Outro resultado foi que as analogias 'naturalizaram-se' na linguagem da Ciência, e sua natureza metafórica ficou dissimulada (Id., Ibid., p. 78).

Falando de seus efeitos para a relação estabelecidos-outsiders, a Ciência não se resume a emprestar legitimidade ao diferencial de poder expresso na relação. Um fator insuspeitado que se coloca na análise da estrutura de desigualdade do racismo, é a posição da Ciência como fonte de conhecimento que reivindica legitimidade como referência para organização da sociedade, que significou, para as sociedades modernas, o entrelaçamento da Ciência com o Estado, para regulamentação da sociedade. Assim o Estado, como instituição social, participa também da relação estabelecidos-outsiders e atua até hoje para conservação desta estrutura de desigualdade que é o racismo.

Para analisar a questão da relação do Estado com o racismo e do lugar do Estado na relação estabelecidos-outsiders basear-se-á aqui no estudo de Santos (1995).

\section{Ciência e Política: uma única vocação}


Da complexa contribuição de Boaventura de Sousa Santos para a compreensão de aspectos decisivos da formação do Estado Moderno, em especial na postura que este adotou em relação ao tratamento da desigualdade, serão evocadas aqui apenas duas conclusões básicas, sem perder de vista que são interligadas e recíprocas, que fundamentarão as reflexões que se seguem. A primeira, a dificuldade da epistemologia moderna em reconhecer o outro.

\begin{abstract}
Efetivamente, a ciência moderna é um paradigma epistemológico assente numa versão extrema de universalismo antidiferencialista cuja hegemonia foi obtida mediante sucessivos epistemicídios cometidos contra os conhecimentos rivais. E como estes conhecimentos foram sempre formas de racionalidade constitutivas de identidades e diferenças socialmente constituídas, os epistemicídios redundaram sempre em identidadecídios. Recorrer, nestas circunstâncias, ao conhecimento moderno para identificar as diferenças não pode deixar de redundar na descaracterização destas (SANTOS, op. cit., p. 43).
\end{abstract}

Mostrada assim a incapacidade da Ciência Moderna (positivista) para lidar de maneira plena com a questão da diferença, Boaventura propõe uma reformulação da Ciência, a adoção de um outro paradigma, que, essencialmente, leve em consideração a questão da multiculturalidade e tenha por pressuposto e por fim o reconhecimento da legitimidade das diferenças étnicas e culturais, incluindo o reconhecimento de outras epistemologias. Tomar partido por tal mudança significa a oposição à invalidação de outras epistemologias, portanto, a retirada significativa das condições de imposição de estigmatização ou de marcadores culturais de diferença negativos.

Outro de seu foco de análise, a dificuldade do Estado moderno de criar políticas públicas de igualdade, é um problema que Boaventura relaciona exatamente a essa incapacidade da epistemologia positivista: "o reconhecimento do outro é uma das fraquezas mais importantes da epistemologia moderna, sobretudo quando posta ao serviço da gestão dos sistemas de desigualdade e de exclusão da modernidade capitalista" (Id., Ibid., p., 47). Como a epistemologia moderna é incapaz de lidar com as 


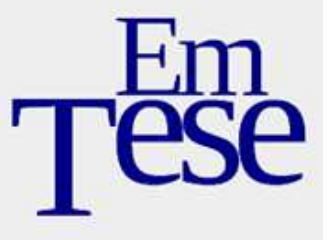

diferenças sem tentar descaracterizá-las, sem tentar transformá-las em desigualdade, o Estado Moderno é também incapaz de lidar com elas sem tentar extingui-las: "Uma política de igualdade que nega as diferenças não inferiorizadoras é, de facto, uma política racista. Como vimos, o racismo, tanto se afirma pela absolutização das diferenças como pela negação absoluta das diferenças.” (Id., Ibid., p. 44).

A análise de Santos é explícita para contribuir para pensar o lugar do Estado na relação estabelecidos-outsiders. Conforme Santos, o Estado moderno capitalista se desenvolveu em torno da função geral de "manter a coesão social numa sociedade atravessada pelos sistemas de desigualdade e de exclusão” (Id., Ibid., p. 7), ou seja, visava a uma gestão controlada, na impossibilidade de eliminá-los, e no benefício às classes dominantes de não eliminá-los, dos sistemas de desigualdade e de exclusão ambos sistemas que caracterizam-se pela instituição de uma relação estabelecidosoutsiders. Conforme Santos, “os princípios básicos da cidadania e dos direitos, da reinserção e do assimilacionismo têm no Estado moderno capitalista a sua instituição privilegiada" (Id., Ibid., p. 7), e esses princípios eram acionados não objetivando a efetivação da igualdade social, mas visando exatamente à manutenção da desigualdade e da exclusão, ao manter estas 'sob controle', ou seja, em níveis em que não ameacem a coesão social.

A proposta de Santos, então, é a "reinvenção do Estado", para um Estado que, assim como a nova epistemologia proposta, leve em consideração centralmente a questão da multiculturalidade, e tenha preocupação constante e ativa com sua preservação. Ter esta consideração como central implica um Estado não racista.

A Ciência Positiva e o Estado Moderno, duas esferas que reivindicam a legitimidade do monopólio sobre a ordenação do social, atuaram ambas em conjunto, com o despotismo que lhes era inerente, para atender a um único desejo totalitário: 


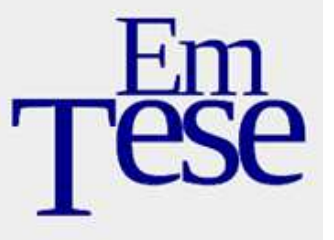

impor a verdade europeia sobre todo o mundo, e com esta, a supremacia da civilização europeia sobre o globo, através da atividade do Estado em se empenhar pela imposição e manutenção da desigualdade e da exclusão. Ambos foram construídos sobre o racismo, e ambos emprestaram sua força para fortalecê-lo. Ambos fazem parte assim de uma grande relação estabelecidos-outsiders que é a estrutura de poder do racismo.

Citadas por Santos, as obtusas políticas públicas de igualdade eram os principais mecanismos pelos quais - oficialmente - o Estado interferia ativamente na sociedade no sentido da oposição à desigualdade. Entretanto, uma outra forma de atuação, que se desenvolveu a partir daquela, é reivindicada pelos grupos que lutam contra a desigualdade, por se considerar que sejam as que atinjam com mais precisão o âmago do problema: as políticas públicas de discriminação positiva.

Diante da inserção de Estado e Ciência configuração da relação estabelecidosoutsiders, a luta dos grupos outsiders contra a marginalização faz-se bastante complexa e delicada. Para os limites deste artigo, tratar-se-á unicamente de uma modalidade desta luta, a luta por políticas públicas de ação afirmativa, como forma de lutar contra a estrutura de poder e desigualdade que é o racismo, uma forma de desestabilizar as legitimações da relação estabelecidos-outsiders.

\section{Por uma outra relação social com a diferença}

No que concerne à importância das ações afirmativas, Carlos Moore Wedderburn (2005), mostra como o racismo é um crime contra a humanidade: "Um crime contra a espécie humana, cometido de forma permanente e voluntária, contra todos os integrantes de uma determinada população-alvo.” E faz reflexões que podem ser 


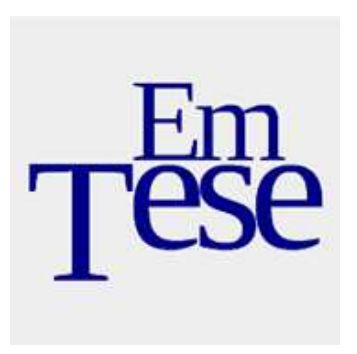

facilmente relacionadas com as de Santos, na sua defesa de um Estado Multicultural, ao incursionar, por exemplo, no terreno da discussão teórica sobre a democracia:

O racismo cria inter-relações desestruturantes e desequilibrantes, que conduzem, inexoravelmente, à implosão de todo o conjunto da sociedade. A democracia no seu sentido mais geral, seja articulada no gênero, na classe social, na orientação sexual, no pertencimento cultural ou, simplesmente, no banal jogo sucessório dos partidos políticos, não terá uma ancoragem duradoura na América Latina [e, pode-se estimar, em nenhuma parte do mundo], região de tendências autoritárias, sem o desmantelamento do seu modelo de relações raciais (WEDDERBURN, op. cit., p. 325).

Ainda nesse contexto de reflexão sobre a democracia, Wedderburn introduz a questão central: "Como estruturar uma ordem social equitativa, uma democracia social de fato, que poderia ser a base de sociedades capazes de prosperar nas condições específicas do século XXI?” (Id., Ibid., p. 328). Partindo do princípio de que o desmonte teórico do racismo, a comprovação científica de sua total falta de fundamentos, não é suficiente para bani-lo do tecido social ${ }^{3}$, é que Wedderburn situa a necessidade das ações afirmativas, colocando-a como uma resposta mesmo à questão que formulou:

Essas questões estão por trás das demandas por políticas públicas de ação afirmativa, capazes de conter as forças centrífugas geradas pelas desigualdades sociais e raciais e de impedir a implosão da sociedade. Através desses mecanismos seria possível reverter as condições de marginalização das populações-alvo do racismo e estancar a ação dos fatores que conduzem as nações latino-americanas [e de todo o mundo] a um beco sem saída. Tratase, portanto, de reatualizar e readequar o processo abolicionista à exigências que se inscrevem neste século (Id., Ibid., p. 328).

Na sequência, Wedderburn enfatiza o papel do Estado no estabelecimento dessa democracia, ao considerar que "as formas de dominação a serem eliminadas e as formas

\footnotetext{
3 “A ideia de que o racismo não pode ser vencido é tão infundada quanto a de que ele cederá facilmente aos apelos à razão.” (WEDDERBUM, 2005, p. 327).
} 


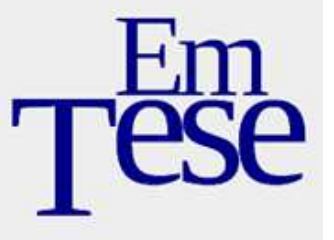

de emancipação a serem atingidas não se sustentam na esfera da construção ideológica, mas na esfera problemática da consciência historicamente construída." Portanto, é crucial nesse processo reforçar o protagonismo, a necessidade e, sobretudo, a “capacidade de intervenção do Estado (...) na formulação de uma estratégia global e articulada, em nível nacional, para a mudança definitiva da situação étnico-racial" (Id., Ibid., p. 328).

No mundo todo, conforme Wedderburn, e esse é mais um dos motivos para que ele defenda as ações afirmativas como melhor forma de atacar e resolver o problema, a implementação de políticas públicas de ação afirmativa tem se mostrado eficaz a curto prazo na redução das iniquidades raciais e sociais.

Assim como Wedderburn enfatiza o protagonismo do Estado nesse esforço, Sabrina Moehlecke (2002), também concorda que a ideia de uma ação afirmativa se desenvolve a "exigindo que o Estado, para além de garantir leis anti-segregacionistas, viesse também a assumir uma postura ativa para a melhoria das condições para a população negra.” (MOEHLECKE, op. cit., p. 198).

Também tratando as ações afirmativas do ponto de vista de seu potencial para ampliação para democratização social, Sabrina Moehlecke mostra como o processo de redemocratização no Brasil - fornecendo subsídios para pensar processos de redemocratização e de ampliação da democracia no mundo todo - é incompleto, ou seja, permeado por diversas lacunas não resolvidas.

Uma delas refere-se à permanência de condições adscritas, isto é, características não mutáveis inerentes a um indivíduo, como cor e sexo, a influir na definição das oportunidades de ingresso no mercado de trabalho, progressão na carreira, desempenho educacional, acesso ao ensino superior, participação na vida política (Id., Ibid., p. 198).

Citando um texto de Sérgio Guimarães, que tem o sugestivo título de "Desigualdade que anula a desigualdade: notas sobre a ação afirmativa no Brasil", 


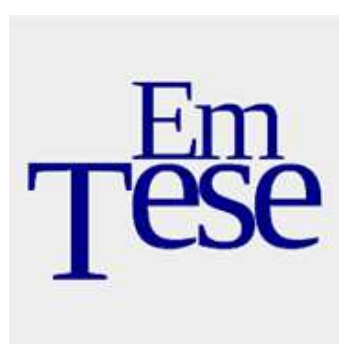

Moehlecke recorre à teorização de Guimarães sobre as ações afirmativas e sua atuação e inserção precisas na sociedade e na teoria democrática.

\begin{abstract}
Antonio Sergio Guimarães (1997) apresenta uma definição da ação afirmativa baseado em seu fundamento jurídico e normativo. A convicção que se estabelece na Filosofia do Direito, de que tratar pessoas de fato desiguais como iguais, somente amplia a desigualdade inicial entre elas, expressa uma crítica ao formalismo legal e também tem fundamentado políticas de ação afirmativa. Estas consistiriam em "promover privilégios de acesso a meios fundamentais - educação e emprego, principalmente - a minorias étnicas, raciais ou sexuais que, de outro modo, estariam deles excluídas, total ou parcialmente." $(1997,233)$. Além disso, a ação afirmativa estaria ligada a sociedades democráticas, que tenham no mérito individual e na igualdade de oportunidades seus principais valores. Desse modo, ela surge "como aprimoramento jurídico de uma sociedade cujas normas e mores pautam-se pelo princípio da igualdade de oportunidades na competição entre indivíduos livres", justificando-se a desigualdade de tratamento no acesso aos bens e aos meios apenas como forma de restituir tal igualdade, devendo, por isso, tal ação ter caráter temporário, dentro de um âmbito e escopo restrito (1997, 233). Essa definição sintetiza o que há de semelhante nas várias experiências de ação afirmativa, qual seja, a ideia de restituição de uma igualdade que foi rompida ou que nunca existiu (MOEHLECKE, op. cit., p. 200).
\end{abstract}

Quanto à restituição da igualdade, a autora evidencia a versatilidade das ações afirmativas como instrumento de ampliação da democracia, exatamente devido à amplitude de seu escopo de atuação, mostrando como seu público-alvo pode variar de acordo com as situações existentes e abranger grupos como minorias étnicas, raciais, e mulheres (Id., Ibid., p. 199).

Além da sua possibilidade de atuação quanto à desigualdade, Moehlecke fala de outra dimensão possível das políticas de ação afirmativa: a sua relação com o tema da diversidade. Conforme a autora, as ações afirmativas partem da "necessidade de combater sistematicamente a discriminação existente em certos espaços na sociedade, e de reduzir a desigualdade que atinge certos grupos, como aquela marcada pela raça ou gênero", vinculando assim seu potencial na luta de grupos outsiders contra a desigualdade e marginalização de que são vítimas. 


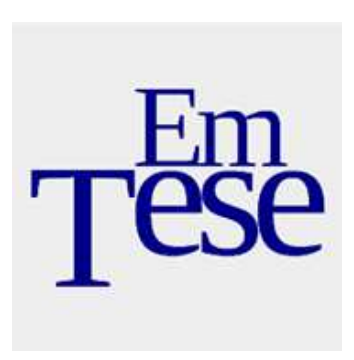

\title{
6. Ações afirmativas e a desnaturalização da desigualdade
}

Fundamental na reflexão dos autores estudados é a ênfase que dão, como nas palavras de Sabrina Moehlecke, à "relação entre discriminação e desigualdades sociais" (MOEHLECKE, op. cit., p. 201). Este aspecto da questão denota como uma relação estabelecidos-outsiders atua para reinventar e reproduzir constantemente a desigualdade que institui.

Quanto a este aspecto, Ricardo Henriques (2001) já havia mostrado como racismo e desigualdades sociais se retroalimentam, e como a naturalização das desigualdades sociais contribui para o fortalecimento do racismo:

\begin{abstract}
As origens históricas e institucionais da desigualdade brasileira são múltiplas, mas sua longa estabilidade faz com que o convívio cotidiano com ela passe a ser encarado, pela sociedade, como algo natural. (...) A naturalização da desigualdade, por sua vez, engendra no seio da sociedade civil resistências teóricas, ideológicas e políticas para identificar o combate à desigualdade como prioridade das políticas públicas. Procurar desconstruir essa naturalização da desigualdade encontra-se, portanto, no eixo estratégico de redefinição dos parâmetros de uma sociedade mais justa e democrática (HENRIQUES, op. cit., p. 1).
\end{abstract}

Considerando-se que o pertencimento racial tem papel decisivo na estruturação das desigualdades econômicas e sociais, Henriques defende que a questão da desigualdade racial precisa ser incorporada como elemento central do debate pela igualdade social e pela democratização. "Desnaturalizar a desigualdade econômica e social no Brasil passa, portanto, de forma prioritária por desnaturalizar a desigualdade racial." (Id., Ibid., p. 2).

A relação do racismo como obstáculo à democracia é talvez menos evidente. No entanto, é bem formulada por Wedderburn: "O racismo favorece, alimenta e encoraja o 


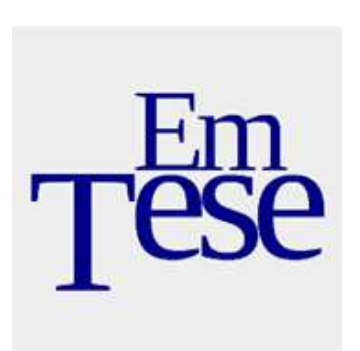

totalitarismo político, o despotismo cultural e as desigualdades socioeconômicas em geral.” (WEDDERBURN, op. cit., p. 330), constituindo entrave significativo, então, à democracia.

Nesse contexto em que inclusive Estado e Ciência, duas instituições de muito poder e prestígio e que reivindicam neutralidade e validade universal, contribuíram para disseminação e fortalecimento do racismo, as ações afirmativas, são uma barreira eficaz à progressão do racismo e às desigualdades sociais nele alicerçadas, e importante instrumento na mobilização e luta política dos povos que sofrem com o racismo na luta contra desigualdade e marginalização e para o estabelecimento efetivo da igualdade social e equidade étnico-racial e de gênero.

\section{Considerações finais}

O racismo, como estrutura social de poder, é uma típica expressão de uma relação estabelecidos-outsiders, na qual um grupo monopoliza os meios de poder e estabelece o outro grupo como portador de status humano degenerado e inferior. A identidade do grupo mais poderoso em oposição ao outro é fundada em marcadores sociais de diferença recrutados para tanto, cujo conteúdo, quando questionado, é maleável e mutável para garantir a permanência da desigualdade. Outras instituições e fenômenos sociais, como Ciência e Estado, também são colocadas em favor dos grupos mais poderosos de modo a manter o diferencial de poder.

A luta dos grupos outsiders contra esta imposição de uma estrutura societária desigual tem muitas complexidades. Discutiu-se aqui a ação afirmativa como modalidade da luta contra o racismo, pelo potencial que os próprios intelectuais e povo negro em luta veem nela como instrumento importante na luta pela igualdade. 


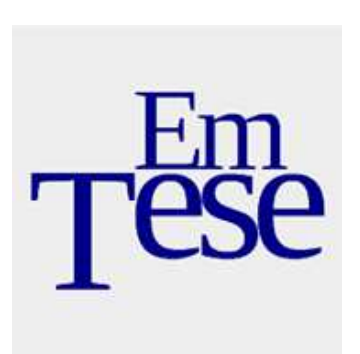

A abordagem estrutural, por meio do par categorial estabelecidos-outsiders elaborado por Norbert Elias, revela que numa estrutura social de desigualdade, como a do racismo, o conteúdo específico do marcador social, que visa a legitimar a desigualdade e a inferioridade de um grupo, é bastante elástico e pode variar enormemente no sentido de manter sua efetividade como legitimador da desigualdade. O decisivo na manutenção de uma estrutura de poder tal qual o racismo não é a verdade do marcador de diferença, donde se presumiria que a comprovação de sua inverdade seria suficiente para perda de sua validade; o decisivo é a estrutura de poder, e esta faz recurso a todos os argumentos, representações e instituições que puder atrair para conservar-se.

Neste sentido, a ação afirmativa aparece com grande potencial na luta por atuar conferindo poder aos grupos outsiders, vítimas de estigmatização e marginalização. Tendo mais poder social, ocupando postos no Estado e na Ciência, estes grupos podem atuar desequilibrando estas estruturas de poder e desigualdade nas quais estão envolvidos. Como a estrutura de desigualdade se mantém sobre uma correlação de forças, a ação afirmativa constitui-se em modalidade estratégica de luta por desestabilizar os diferencias de poder que sustentam o racismo.

\section{Referências}

BEAUVOIR, Simone de. O segundo sexo. 2ed. São Paulo: Difusão Europeia do Livro, [1970]. 2v.

BRAH, Avtar. Diferença, diversidade, diferenciação. Cadernos Pagu (26), janeirojunho de 2006: pp.329-376. 


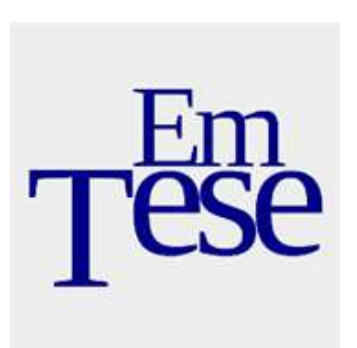

ELIAS, Norbert e SCOTSON, John L. Os estabelecidos e os outsiders: sociologia das relações de poder a partir de uma pequena comunidade. Rio de Janeiro: J. Zahar, 2000.

GUIMARÃES, Antonio Sergio Alfredo. Como trabalhar com "raça" em Sociologia. Educação e Pesquisa, São Paulo, v.29, n.1, p. 93-107, jan./jun. 2003.

HENRIQUES, Ricardo. Desigualdade racial no Brasil: evolução das condições de vida na década de 90. Texto para discussão nº 807. Brasília: IPEA, 2001.

MALRAUX, André. Le Miroir des limbes. Paris : Pléiade, Gallimard, 1976.

MOEHLECKE, Sabrina. Ação Afirmativa: História e debates no Brasil. Cadernos de Pesquisa, n.117, 2002, p.197-217.

MUNANGA, Kabengele. "Uma abordagem conceitual das noções de raça, racismo, identidade e etnia". In: BRANDÃO, André Augusto P. (Org.). Cadernos PENESB, n. 05, Niterói, RJ: EdUFF, 2004.

SANTOS, Boaventura S. A construção multicultural da igualdade e da diferença. Palestra proferida no VII Congresso Brasileiro de Sociologia. Rio de Janeiro, 1995.

STEPAN, Nancy Leys. "Raça e Gênero: O papel da analogia na ciência". In: Tendências e Impasses. Rio de Janeiro: Roccio, 1994.

WEDDERBURN, Carlos Moore. "Do marco histórico das políticas de ação afirmativa. Gênese das políticas de ações Afirmativas e Questões afins". In: Ações Afirmativas e Combate ao Racismo nas Américas. Coleção Educação para Todos. Brasília, 2005. 


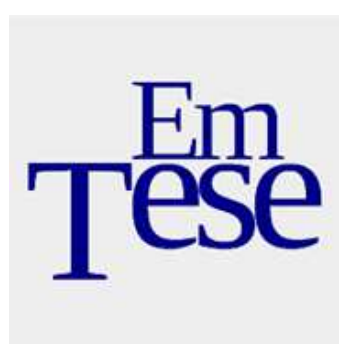

\section{Sociogênese do racismo: raça, ações afirmativas e democracia}

Resumo: Este trabalho reflete sobre o racismo, como estrutura de desigualdade e de poder. Sua originalidade funda-se na tentativa de buscar aprofundar as reflexões sobre a temática racial aplicando a ela a teoria das relações de poder elaborada por Elias (2000), centrada no par categorial estabelecidos-outsiders. O artigo realiza assim uma análise sociológica do fenômeno do racismo, faz reflexões sobre sua gênese, seu modo de desenvolvimento e suas ligações à Ciência e ao Estado Modernos. Instrumentado por esta abordagem, o artigo encerra refletindo sobre a complexidade da luta antirracismo e as potencialidades das ações afirmativas na luta por igualdade.

Palavras-chave: Racismo. Relações de Poder. Ações Afirmativas.

\section{Sociogenesis of racism: race, affirmative action and democracy}

Abstract: This work reflects on racism, as an inequality and power structure. Its originality is based on the attempt to seek further reflections on racial themes applying to it the theory of power relations developed by Elias (2000), centered on the conceptual pair established-outsiders. The article thus conducts a sociological analysis of the phenomenon of racism, reflects on its genesis, its development mode and its links to Science and the Modern State. Instrumented by this approach, the article concludes by reflecting on the complexity of the anti-racism struggle and the potential of affirmative action in this struggle for equality.

Key-Words: Racism. Power Relationships. Affirmative Actions.

Recebido em: 28 de maio de 2015

Aceito para publicação em: 22 de junho de 2015 